\title{
AVALIAÇÃO DA QUALIDADE MICROBIOLÓGICA DO QUEIJO MINAS FRESCAL PRODUZIDO POR LATICÍNIOS DO ESTADO DE MINAS GERAIS
}

\section{Evaluation of the microbiological quality of Minas Cheese produced by dairies in the state of Minas Gerais}

\author{
Thaís Conceição Custódio Apolinário ${ }^{I^{*}}$, Gisele Simas dos Santos ${ }^{2}$, \\ Josete Amadeu Almeida Lavorato ${ }^{l}$
}

\begin{abstract}
RESUMO
Este trabalho avaliou a presença de coliformes totais e termotolerantes, Salmonella spp., estafilococos coagulase positiva e Listeria monocytogenes em queijos Minas Frescal, produzidos por diferentes indústrias da região da Zona da Mata Mineira fiscalizadas por Serviços de Inspeção Federal, Estadual ou Municipal, num total de 31 amostras de queijos Minas Frescal. Foram encontradas 77,4\% das amostras com contagens superiores ao preconizado pela legislação para coliformes totais, $54,8 \%$ para coliformes termotolerantes, $16,12 \%$ para estafilococos coagulase positiva e 9,6\% para Listeria monocytogenes. Nenhuma das amostras apresentou contaminação por Salmonella spp. Diante disso, 80,6\% das amostras analisadas encontravam-se imprópria para o consumo, por apresentar contagem de pelo menos um dos microrganismos analisados fora dos limites especificados pela legislação. Conclui-se que os queijos Minas Frescais não apresentam qualidade microbiológica satisfatória, o que compromete a segurança do alimento para o consumidor.

Palavras-chave: contaminação; Boas Práticas de Fabricação; análise microbiológica.
\end{abstract}

\begin{abstract}
This work evaluated the presence of total coliforms and thermotolerants, Salmonella spp., Staphylococci Positive Coagulase and Listeria monocytogenes

1 Lab Caseus Laboratório de Análise de Alimentos e Água, Rua São Vicente de Paulo, 21, Pirineus, 36700000, Leopoldina, MG, Brasil. E-mail:thaistst@yahoo.com.br

2 Universidade Iguaçu, Departamento de Enfermagem, Itaperuna, RJ, Brasil.

* Autor para correspondência.
\end{abstract}


in Minas Frescal cheeses, produced by different industries from Zona da Mata region in Minas controlled by services of federal, state or local inspection, with an amount of 31 samples of Minas Frescal cheese. $77.4 \%$ of the samples were found with superior scores from that recommended by law for total coliforms, $54.8 \%$ for coliforms thermotolerants, $16.12 \%$ for positive coagulase Staphylococci counting and $9.6 \%$ for Listeria monocytogenes. None of the samples showed contamination by Salmonella spp. Thus, $80.6 \%$ of the analyzed samples were improper for consumption, to present one of the microorganisms analyzed out of the limits specified by law. It leads to conclusion that Minas Frescal cheeses do not have satisfactory microbiological quality, which compromises the safety of the food for the consumer.

Keywords: contamination; good practices; microbiological analysis.

\section{INTRODUÇÃO}

O queijo é um meio de conservação do leite. Em média são gastos dez litros de leite para produzir um quilo de queijo. Sendo assim, ele é a maneira mais simples de se consumir as propriedades nutritivas do leite, sendo indicado em dietas alimentares devido a sua alta digestibilidade quando comparado a outros alimentos (MARTINS; MOURA, 2010).

Devido suas grandes vantagens nutricionais, o queijo possui grande importância nos hábitos de consumo da população brasileira, sendo parte integrante dos hábitos e da cultura nacional. Com a finalidade de evitar contaminações, durante o processo de fabricação do queijo, deve-se atentar para a obtenção do leite de forma higiênica, a sua pasteurização, adoção de Boas Práticas de Fabricação e refrigeração adequada até o consumidor final (SERIDAN et al., 2009).

Entende-se por queijo Minas Frescal, o queijo fresco obtido por coagulação enzimática do leite com coalho e/ou outras enzimas coagulantes apropriadas, complementada ou não com ação de bactérias lácticas específicas (BRASIL, 1997). O queijo Minas Frescal é considerado um queijo semi-gordo (teor de gordura no extrato seco de $25,0 \%$ a $44,9 \%$ ) e de muita alta umidade (acima de 55,0\%) (BRASIL, 1997; BRASIL, 2004).
Por possuir maior rendimento, processamento simples e ausência de maturação do produto final, a produção do queijo Minas Frescal é uma importante atividade da indústria queijeira, que proporciona um retorno rápido dos investimentos e menores custos para o produtor (PASSOS et al., 2009). Os queijos frescos e macios constituem um meio propício para o crescimento de microrganismos patogênicos. No caso do Minas Frescal, suas características físico-química também contribuem para esse potencial risco de crescimento de microrganismos patogênicos (CARVALHO et al., 2007).

Por não possuir período de maturação, o queijo Frescal é um produto perecível que deve ser consumido rapidamente, sendo necessária sua manutenção em ambiente refrigerado (LOGUERCIO; ALEIXO, 2001). As contaminações e as alterações causadas por microrganismos indesejáveis tornam o produto inaceitável ou até mesmo impróprio para o consumo (ROCHA et al., 2006).

As Boas Práticas de Fabricação (BPF) e medidas de sanitização são importantes para a produção de produtos de qualidade. A pasteurização, aplicada ao leite cru antes de ser utilizado na produção do queijo, diminui a população de microrganismos presentes no leite, porém toxinas, como a enterotoxina estafilocócica, não são inativadas 
podendo causar intoxicações alimentares nos consumidores (PICOLI et al., 2006).

A ingestão de queijos contaminados pode trazer consequências para a saúde da população, como, por exemplo, gastroenterites, tornando-se, portanto um problema de saúde pública. Para detectar possíveis contaminações nos alimentos utilizam-se grupos de microrganismos indicadores (coliformes) e patogênicos (PENA et al., 2009). Os microrganismos indicadores quando presentes em alimentos nos fornecem informações sobre a ocorrência de contaminações de origem fecal. Os indicadores mais comuns são os coliformes totais e coliformes fecais, também conhecidos como coliformes termotolerantes (LANDGRAF, 2008).

Dentre alguns microrganismos patogênicos, pode-se destacar a Salmonella spp., que causa infecção alimentar e o Staphylococcus aureus, que é produtor de uma toxina termoestável pré formada no alimento (PENA et al., 2009). Outro patógeno que também pode estar presente nos alimentos é a Listeria spp. que pode causar febre, fadiga, mal-estar podendo haver ou não náusea, vômitos, dores, diarreia e até comprometimento do sistema nervoso central causando meningite, encefalite e abscessos (FRANCO; LANDGRAF, 2008).

O presente trabalho tem como objetivo principal avaliar a qualidade microbiológica do queijo Minas Frescal, produzido e comercializado por laticínios do estado de Minas Gerais, por meio de análises da presença de coliformes totais, coliformes termotolerantes, Salmonella spp., Listeria monocytogenes e estafilococos coagulase positiva.

\section{MATERIAL E MÉTODOS}

\section{Preparo das amostras}

No período entre janeiro a dezembro de 2012, foram analisadas 31 amostras de queijo Minas Frescal, provenientes de 10 diferentes laticínios da região da Zona da Mata Mineira, fiscalizadas pelo Serviço de Inspeção Federal (SIF), Estadual (SIE) ou Municipal (SIM). As análises foram realizadas no Lab Caseus ${ }^{\circledR}$, laboratório de análise de água e alimentos, Leopoldina-MG. Utilizou-se amostragem nãorepresentativa de conveniência. Foram realizadas as seguintes análises: coliformes totais, coliformes termotolerantes, estafilococos coagulase positiva, Salmonela spp., e Listeria monocytogenes, de acordo com os Métodos Analíticos Oficiais para Análises Microbiológicas para controle de produtos de origem animal e água (BRASIL, 2003).

Foram pesadas $25 \mathrm{~g}$ de cada amostra com partes retiradas em pontos distintos do queijo. Essas alíquotas foram diluídas e homogeneizadas em $225 \mathrm{~mL}$ de caldo UVM para Listeria seletivo modificado, da Acumedia ${ }^{\circledR}$ e outro de solução salina peptonada $1,0 \%$, Acumedia ${ }^{\circledR}$. A partir das diluições em solução salina peptonada $1,0 \%$ preparou-se a diluição $10^{-1}$ e as diluições seguintes $10^{-2}$ e $10^{-3}$. As diluições com a solução salina peptonada $1,0 \%$ e o caldo UVM foram posteriormente incubadas a $36 \pm 1^{\circ} \mathrm{C}$ por 16 a 20 horas e a $31 \pm 1^{\circ} \mathrm{C}$ por 24 horas, respectivamente.

\section{Contagem de coliformes totais e coliformes termotolerantes}

As diluições decimais preparadas anteriormente $\left(10^{-2}\right.$ e $\left.10^{-3}\right)$ foram semeadas em placas de Petri onde se verteu dupla camada do meio VRBA (ágar cristal violeta vermelho neutro bile) (Fabricante Acumedia $\left.{ }^{\circledR}\right)$. Em seguida, as placas de Petri foram invertidas e incubadas a $36^{\circ} \mathrm{C} \pm 1$ por 24 h e posteriormente procedeu-se a contagem das colônias típicas que se apresentaram redondas, róseas com ou sem alo de precipitação. As colônias típicas foram inoculadas em tubos contendo caldo VBB (caldo Verde Bile Brilhante 2\% lactosado, Acumedia ${ }^{\circledR}$ ) e caldo EC (Fabricante Difco $^{\circledR}$ ) e incubadas por 24 a $48 \mathrm{~h}$, sendo o 
caldo VBB a $36{ }^{\circ} \mathrm{C} \pm 1$ em estufa e o caldo EC a $45{ }^{\circ} \mathrm{C} \pm 1$ em Banho-Maria com agitação. Foram considerados positivos os tubos que apresentaram efervescência e/ou formação de gás dentro do tubo de Durhan. Calculou-se a população e os resultados foram expressos em unidades formadoras de colônias por grama (UFC/g).

\section{Enumeração de estafilococos coagulase positiva}

Da diluição $10^{-1}$ foi retirado $0,1 \mathrm{~mL}$ e semeado, com auxílio de alça de Drigalski, em placas de Petri previamente plaqueadas com meio ágar BP (Baird-Parker) (Fabricante Acumedia $\left.^{\mathbb{R}}\right)$ e incubadas invertidas por $48 \mathrm{~h}$ a $36{ }^{\circ} \mathrm{C} \pm 1$, sendo consideradas típicas as colônias negras com halo de precipitação. Foram selecionadas três colônias típicas e três colônias atípicas (colônias negras sem halo de precipitação) para a realização da prova de catalase, que consistiu na adição de uma gota de água oxigenada 3\% em uma alíquota da colônia escolhida, sendo a positividade visualizada pela formação de bolhas. As colônias que apresentaram catalase positiva foram inoculadas em meio BHI (Caldo cérebro-coração) (Fabricante Acumedia ${ }^{\circledR}$ ) e incubadas por $24 \mathrm{~h}$ para enriquecimento. Após este período foi retirada uma alíquota de $0,2 \mathrm{~mL}$ e inoculada em $0,5 \mathrm{~mL}$ de plasma de coelho (Fabricante Laborclin ${ }^{\circledR}$ ) e incubado a $36{ }^{\circ} \mathrm{C} \pm 1$ por 4 a $24 \mathrm{~h}$, sendo considerados positivos aqueles tubos que apresentaram formação de coágulo. Calculou-se a população e os resultados foram expressos em UFC/g.

\section{Pesquisa de Salmonella spp.}

Após o período de incubação da solução salina peptonada $1,0 \%$ foram retiradas alíquotas de $1 \mathrm{~mL}$ e inoculadas em meio caldo Tetrationato (TT) (Fabricante Acumedia) e Selenito-Cistina (SC) (Fabricante Acumedia ${ }^{\circledR}$ ) e alíquotas de $0,1 \mathrm{~mL}$ e inoculadas em meio caldo Rappaport Vassiliadis (Fabricante Acumedia $^{\circledR}$ ) e incubados a $41{ }^{\circ} \mathrm{C} \pm 1$ por 24 a $30 \mathrm{~h}$ em banho-maria. Em seguida, com auxílio da alça de platina, procedeu-se a semeadura das amostras nos meio ágar BPLS (Fabricante Acumedia $^{\circledR}$ ) e ágar XLT4 (Fabricante Difco ${ }^{\circledR}$ ) e incubados invertidos a $36{ }^{\circ} \mathrm{C} \pm 1$ por $24 \mathrm{~h}$ sendo positivas as colônias róseas no ágar BPLS e colônias negras ou vermelhas no ágar XLT4. Das colônias consideradas positivas foi escolhida uma e semeada em placas de Petri com meio ágar não diferencial, PCA (Fabricante Acumedia ${ }^{\circledR}$ ). As placas de Petri semeadas foram incubadas invertidas a $36{ }^{\circ} \mathrm{C} \pm 1$ por 18 a 24 horas.

Realizaram-se em seguida as seguintes provas bioquímicas: produção de urease em caldo ureia (Fabricante Acumedia ${ }^{\circledR}$ ), reações em ágar TSI inclinado (Fabricante Acumedia $^{\circledR}$ ), descarboxilação da lisina em ágar LIA inclinado (Fabricante Acumedia ${ }^{\circledR}$ ) e teste de motilidade, produção de $\mathrm{H}_{2} \mathrm{~S}$ e de indol em ágar SIM (Fabricante Acumedia ${ }^{\circledR}$ ). No ágar TSI e ágar LIA, com auxilio de agulha de platina, foi realizada a picada profunda do meio com o estriamento do bisel, a partir das colônias retiradas do ágar PCA. No ágar SIM, ainda com agulha de platina e a colônia retirada do ágar PCA, foi realizada a picada profunda do meio. No caldo ureia foi diluída uma alíquota da mesma colônia retirada do ágar PCA. A motilidade foi caracterizada pela difusão do crescimento bacteriano por todo o meio, se o crescimento for restrito à linha de semeadura, indica que o microrganismo é considerado imóvel. A produção de $\mathrm{H}_{2} \mathrm{~S}$ foi observada por meio da sua reação com $o$ citrato de ferro e amônio (presentes no meio), formando um precipitado negro insolúvel. Após a leitura da motilidade e da produção de $\mathrm{H}_{2} \mathrm{~S}$, adicionou-se quatro gotas de reativo de Kovac's aos tubos para verificar se houve produção de indol, que foi observado pela formação de um anel vermelho. O padrão de tipicidade nos demais meios de cultura é 
observado da seguinte forma: no ágar TSI é verificado pela apresentação de alcalinidade no bisel que se apresentou da cor vermelha, no ágar LIA ocorre a manutenção da cor violeta no fundo do tubo, devido à manutenção da alcalinidade do ágar LIA e no caldo ureia ocorre a viragem de amarelo para rosa intenso.

Os resultados típicos nas provas bioquímicas são: a maioria das Salmonelas não produzem urease e apresentam no TSI as seguintes reações: ácido na base (amarelo), com ou sem produção de gás, alcalino ou inalterado no bisel (vermelho), com ou sem produção de $\mathrm{H}_{2} \mathrm{~S}$. A maioria das Salmonelas é capaz de produzir lisina descarboxilase, que tem como produto a cadaverina e o $\mathrm{CO}_{2}$ deixando o meio alcalino e evitando a viragem de cor mantendo então a cor violeta no fundo do tubo. A maioria das Salmonelas apresenta motilidade positiva e são produtoras de $\mathrm{H}_{2} \mathrm{~S}$. Quase a totalidade das Salmonelas não produz indol.

Para confirmação, as amostras típicas no ágar TSI e no ágar LIA foram semeadas, com uso da alça de platina, no meio ágar Bismuto Sulfito (Fabricante Merck $^{\circledR}$ ), incubadas invertidas a $36{ }^{\circ} \mathrm{C} \pm 1$ por 24 a $48 \mathrm{~h}$ sendo típicas as colônias negras esverdeadas com ou sem brilho metálico. Em seguida realizou-se coloração de Gram buscando encontrar cocobacilos Gram negativos. Como segunda prova confirmativa utilizou-se meio cromogênico CromoCen SC ${ }^{\circledR}$ (Fabricante Biocen $^{\circledR}$ ), neste meio o crescimento de colônias típicas foi observado pela presença de colônias róseas com halo opaco. O resultado foi expresso como ausência ou presença em $25 \mathrm{~g}$.

\section{Pesquisa de Listeria monocytogenes}

Após o período de enriquecimento seletivo em caldo UVM, alíquotas de $0,1 \mathrm{~mL}$ das amostras foram inoculadas em caldo Fraser (Fabricante Acumedia ${ }^{\circledR}$ ) e incubadas a $31{ }^{\circ} \mathrm{C} \pm 1$ por 24 a $48 \mathrm{~h}$. Em seguida realizouse o isolamento seletivo. As amostras foram semeadas por estriamento, com auxílio da alça de platina, em Ágar Oxford (Fabricante Acumedia $^{\mathbb{R}}$ ) e Ágar Palcam (Fabricante Acumedia $^{\circledR}$ ) que foram incubados a $31{ }^{\circ} \mathrm{C} \pm 1$ por 24 a 48 h. Foram escolhidas as colônias negras com halo escuro em Ágar Oxford e verdeamarelada com zona escura em Ágar Palcam. Em seguida realizou-se coloração de Gram, buscando encontrar bacilos curtos Gram positivos. As amostras com células típicas no Gram foram estriadas em placas de CromoCen Listeria (Base ALOA) ${ }^{\mathbb{}}$ (Fabricante Biocen ${ }^{\circledR}$ ) e incubadas a $31^{\circ} \mathrm{C} \pm 1$ por $48 \mathrm{~h}$, sendo realizadas assim as etapas de confirmação e identificação, considerando positivas as colônias azul-esverdeadas rodeadas com halo opaco. $\mathrm{O}$ resultado foi expresso como ausência ou presença em $25 \mathrm{~g}$.

\section{RESULTADOS E DISCUSSÃO}

Nos dados apresentados na Tabela 1, observa-se que das 31 amostras analisadas de queijo Minas Frescal, 24 (77,4\%) amostras apresentaram valores acima do recomendado pela legislação vigente para coliformes totais e 17 amostras $(54,8 \%)$ para coliformes termotolerantes. A presença desse último microrganismo pode ser utilizada como um indicativo da possível presença de patógenos como Escherichia coli, que pode causar riscos à saúde dos consumidores (SALOTTI et al., 2006; NUNES et al., 2013).

Os coliformes termotolerantes presentes em queijos fabricados com leite pasteurizado podem estar relacionados com falhas no processo de pasteurização ou recontaminação pós-pasteurização, tais como problemas de manipulação e de aplicação correta de Boas Práticas de Fabricação (SALOTTI et al., 2006; O’BRIEN et al., 2009 ). Além dos coliformes termotolerantes, os totais também podem ser reduzidos pela aplicação das Boas Práticas de Fabricação. Costa Dias et al. (2012) verificaram uma redução significativa na contagem de coliformes totais nas mãos 
dos manipuladores após a aplicação das Boas Práticas de Fabricação em um laticínio.

Em relação à contagem de estafilococos coagulase positiva, $16,12 \%$ das amostras estavam acima do limite permitido pela legislação de 5,0 x 10² UFC/g (BRASIL, 1996). Assim como nos coliformes, altas contagens de Staphylococcus spp. estão relacionadas a problemas de processamento: falhas de pasteurização, higienização inadequada de equipamentos e manipuladores e temperaturas de estocagem incorretas (FORSYTHE, 2002).

Quanto à contagem de Salmonella spp. foi encontrada ausência em $25 \mathrm{~g}$ em todas as amostras de queijo Minas Frescal analisadas (Figura 1). No entanto, verificou-se a presença de Listeria monocytogenes em $9,6 \%$ das amostras, o que não está conforme o preconizado pela legislação que é a ausência em 25g (Figura 1). A Listeria monocytogenes é um patógeno de origem alimentar (CALLON et al., 2011). Sua presença em queijos está relacionada com a habilidade de sobrevivência e/ou crescimento em queijos (JAKOBSEN et al., 2011; SCHVARTZMAN et al., 2011).
Além disso, Listeria monocytogenes é comumente encontrada em ambientes de processamento de queijo (CARPENTIER; CERF, 2011). A falta de procedimentos adequados de limpeza e sanitização, o acúmulo de soro no chão e um ambiente de processamento sem ventilação que provoca condensação e umidade nas paredes e tetos são as principais causas de crescimento de Listeria monocytogenes em uma fábrica de queijo (COSTA DIAS et al., 2012).

Para reduzir o risco de bactérias patogênicas, no processamento de queijos é necessário a pasteurização do leite, a maturação prolongada e o controle de temperatura de estocagem, associado com fatores intrínsecos como $\mathrm{pH}$, atividade de água e a presença de compostos antimicrobianos produzidos pelas bactérias lácticas. Além de um programa eficiente de limpeza e sanitização dos equipamentos e ambiente de produção (KOUSTA et al., 2010). No entanto, o queijo Minas Frescal pelas suas próprias características como alto teor de umidade, associado com o baixo teor de sal

Tabela 1 - Análises microbiológicas em 31 amostras de queijo Minas Frescal produzidos na Zona da Mata mineira durante o período de janeiro a dezembro de 2012

\begin{tabular}{ccccc}
\hline Microrganismos & UFC/g & $\begin{array}{c}\text { Número } \\
\text { de } \\
\text { amostras } \\
\text { analisadas }\end{array}$ & $\begin{array}{c}(\%) \text { de amostras } \\
\text { analisadas em } \\
\text { relação ao total } \\
\text { de amostras }\end{array}$ & $\begin{array}{c}\text { Limite aceitável } \\
\text { estabelecido pela } \\
\text { legislação } \\
\text { (BRASIL, 1996) }\end{array}$ \\
\hline Coliformes & $1,1 \times 10^{3}-1,5 \times 10^{4}$ & 7 & 22,58 & \\
totais & $1,6 \times 10^{4}-1,5 \times 10^{5}$ & 3 & 22,58 & \\
Coliformes & $>1,5 \times 10^{5}$ & 14 & 9,67 & $1,0 \times 10^{3} \mathrm{UFC} / \mathrm{g}$ \\
termotolerantes & $5,1 \times 10^{3}-5 \times 10^{4}$ & 3 & 45,16 & \\
& $>5,0 \times 10^{4}$ & 8 & 45,16 & \\
\hline Estafilococos & $<5,0 \times 10^{2}$ & 26 & 25,8 & $5,0 \times 10^{2} \mathrm{UFC} / \mathrm{g}$ \\
coagulase positiva & $>5,0 \times 10^{2}$ & 5 & 83,87 & $5,0 \times 10^{2} \mathrm{UFC} / \mathrm{g}$ \\
\hline
\end{tabular}


e ausência de maturação tornam esse queijo susceptível de contaminações, causadas tanto pelo leite utilizado em sua produção quanto por contaminações cruzadas no pósprocessamento (PASSOS et al., 2009).

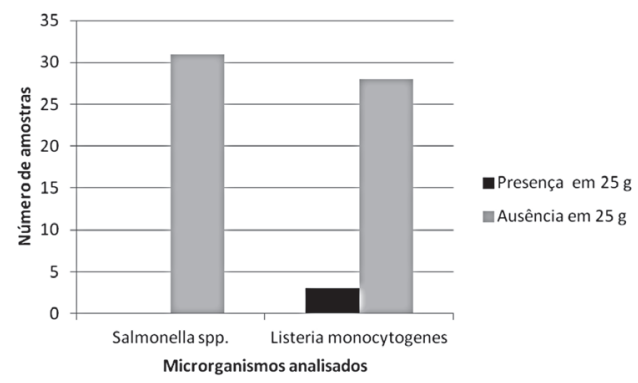

Figura 1 - Pesquisa de Salmonella spp. e Listeria monocytogenes em 31 amostras de queijo Minas Frescal produzidas na Zona da Mata mineira.

A presença de qualquer um dos microrganismos analisados no presente trabalho em valores acima do exigido pela legislação torna o queijo Minas Frescal impróprio para o consumo humano, o que foi verificado em $80,6 \%$ das amostras analisadas. A ingestão de um queijo Minas Frescal microbiologicamente fora dos padrões pode causar vários sintomas que vão desde incômodos intestinais, diarreia, vômitos e gastroenterites até meningite e encefalite, dependendo do tipo e da quantidade de microrganismo que está presente no produto ingerido (FRANCO; LANDGRAF, 2008).

Verifica-se que a má qualidade microbiológica de queijo Minas Frescal é recorrente em outros trabalhos da literatura. Ferreira et al. (2011) quantificaram coliformes totais e coliformes termotolerantes em queijo Minas Frescal. Do total de 20 amostras analisadas pelos autores $14(70,0 \%)$ apresentaram contaminação por coliformes totais e $16(80,0 \%)$ amostras apresentaram contaminação para coliformes termotolerantes. A técnica eleita pelos pesquisadores foi a técnica de número mais provável. Embora tenha sido utilizada técnica diferente, o estudo de Ferreira et al. (2011) se assemelha ao presente estudo devido a reprovação de uma grande porcentagem dos queijos analisados, no que se refere a contaminação por coliformes totais e coliformes termotolerantes.

Em outro estudo Loguercio; Aleixo (2001) avaliaram a microbiologia de 30 amostras de queijo Minas Frescal, adquiridas em dois pontos tradicionais na comercialização de produtos coloniais no centro de Cuiabá, Mato Grosso. Das 30 amostras analisadas, $28(93,33 \%)$ amostras encontravam-se com contagem acima do padrão previsto pela legislação para coliformes termotolerantes e $29(96,67 \%)$ amostras apresentavam contagens superiores ao preconizado pela legislação para estafilococos coagulase positiva. Assim como no presente trabalho, detectou-se contaminação por coliformes termotolerantes e estafilococos coagulase positiva.

Almeida Filho; Nader Filho (2000) avaliaram a ocorrência de estafilococos coagulase positiva em queijo Minas Frescal comercializados na cidade de Poços de Caldas. Os autores avaliaram 80 amostras de queijos Minas Frescal, coletadas em 20 pontos diferentes, sendo verificado pelos autores que 40 $(50 \%)$ amostras estavam fora do permitido pela legislação.

Arruda et al. (2007) avaliaram a presença de estafilococos coagulase positiva em valores acima do preconizado nas 42 amostras de queijos Minas Frescal analisadas, comercializadas em feiras livres na cidade de Goiânia-GO. Essa contaminação elevada pode ser atribuída ao fato do queijo analisado ser comercializado em feiras livres, tendo assim, uma maior manipulação facilitando a contaminação.

Carvalho et al. (2007) avaliaram 31 amostras de queijo Minas Frescal produzido por acidificação direta, 31 amostras fabricadas com uso de fermento láctico e 31 amostras fabricadas por ultrafiltração. Verificaram que $64,5 \%$ e $29 \%$ das amostras de queijo 
fabricadas respectivamente, por acidificação direta e com fermento láctico estavam acima do permitido pela legislação para coliformes termotolerantes. Também encontraram que $12,9 \%$ e $9,7 \%$ das amostras produzidas, respectivamente, por acidificação direta e adição de fermento láctico estavam acima do preconizado para estafilococos coagulase positiva. O queijo fabricado por ultrafiltração apresentou a melhor qualidade microbiológica.

Outro estudo, realizado por Komatsu et al. (2010), também apresentou valores elevados para estafilococos coagulase positiva em queijo Minas Frescal comercializados na cidade de Uberlândia. Os pesquisadores observaram que $88,0 \%$ das amostras estavam contaminadas com níveis inaceitáveis para estafilococos.

Nunes et al. (2013) verificaram que $13 \%$ das amostras de leite e derivados lácteos comercializadas no Distrito Federal foram rejeitadas pelas altas contagens de coliformes termotolerantes, encontradas principalmente em queijos Minas Frescal.

Utilizando-se da metodologia baseada no protocolo da ISO 11290-1 para Ágar cromogênico CromoCen Listeria (Base ALOA $)^{\circledR}$, Santos (2010) avaliou o comportamento microbiológico de 18 amostras de queijo Minas artesanal da microrregião do Serro - MG, em diferentes tempos e temperaturas de maturação. Não foram encontradas Listeria monocytogenes em nenhuma das amostras. Ramos; Costa (2003) utilizando metodologia tradicional da FDA (Food and Drug Administration) analisaram 58 amostras de queijos de coalho artesanal de Manaus - AM, dentre as quais uma apresentou contaminação para Listeria monocytogenes e outra para Listeria innocua.

Zaffari et al. (2007) analisaram a qualidade microbiológica de queijos artesanais comercializados em estradas do litoral norte do Rio Grande do Sul através de metodologia convencional para Listeria. Das 80 amostras analisadas $13(16,0 \%)$ estavam contaminadas por Listeria spp., sendo destas amostras, 03 positivas para Listeria monocytogenes. Em outro estudo realizado no estado do Rio Grande do Norte, Feitosa et al. (2003) detectaram presença de Listeria sp. em 9,0\% das amostras de queijo de coalho e em $15,0 \%$ das amostras de queijo de manteiga. As análises foram realizadas através do teste ELISA, mas a presença de Listeria monocytogenes não foi confirmada pelo método convencional.

\section{CONCLUSÕES}

A presença de microrganismos como coliformes totais e termotolerantes, estafilococos coagulase positiva e Listeria monocytogenes acima do preconizado pela legislação indicam uma má qualidade microbiológica do queijo Minas Frescal e o torna impróprio para o consumo.

Observa-se a necessidade da implantação de melhorias do controle da produção, por meio de boas práticas de fabricação, além da fiscalização efetiva pelos órgãos competentes, para fornecer aos consumidores queijos que não ofereçam riscos à sua saúde.

\section{REFERÊNCIAS}

ALMEIDA FILHO, E. S. de; NADER FILHO, A. Ocorrência de Staphylococcus aureus em queijo tipo "Frescal". Revista de Saúde Pública, v. 34, n. 6, p. 578-580, 2000.

ARRUDA, M. L. T. et al. Ocorrência de Staphylococcus coagulase positiva em queijos tipos Frescal e Padrão comercializados nas feiras-livres de Goiânia - GO. Revista do Instituto Adolfo Lutz, v. 66, n. 3, p. 292$298,2007$.

BRASIL. Ministério da Agricultura, Pecuária e Abastecimento. Departamento de Inspeção de Produtos de Origem Animal. Instrução Normativa $n^{\circ} 62$, de 26 de agosto de 2003. Oficializa os métodos analíticos oficiais para 
análises microbiológicas para controle de produtos de origem animal e água. Diário Oficial da República Federativa do Brasil, Brasília, 18 set. 2003. Seção 1, p. 14.

BRASIL. Ministério da Agricultura, Pecuária e Abastecimento. Portaria $n^{\circ} 146$ de 07 de março de 1996. Regulamento Técnico de Identidade e Qualidade de Queijos e Regulamento Técnico Geral para a Fixação dos Requisitos Microbiológicos de Queijos. Aprova os Regulamentos Técnicos de Identidade e Qualidade de Produtos Lácteos. Diário Oficial da República Federativa do Brasil, Brasília, 11 mar. 1996. Seção1, p. 3977.

BRASIL. Ministério da Agricultura e Abastecimento. Portaria $n^{\circ} 352$ de 04 de setembro de 1997. Aprova o Regulamento Técnico para Fixação de Identidade e Qualidade de Queijo Minas Frescal. Diário Oficial da República Federativa do Brasil, Brasília, 08 set. 1997. Seção1, p. 19684.

BRASIL. Ministério da Agricultura, Pecuária e Abastecimento. [Aditivos no Regulamento Técnico para Fixação de Identidade e Qualidade do Queijo Minas Frescal]. Instrução Normativa $n^{\circ} 4$, de 01 de março de 2004. Diário Oficial da República Federativa do Brasil, Brasília, 5 mar. 2004.

CALLON, C. et al. Ripening conditions: a tool for the control of Listeria monocytogenes in uncooked pressed type cheese. Food Control, v. 22, n. 12, p. 1911-1919, 2011.

CARPENTIER, B.; CERF, O. Review e persistence of Listeria monocytogenes in food industry equipment and premises. International Journal of Food Microbiology, v. 145, p. 1-8, 2011.

CARVAlHO, J. D. G.; ViOTTO, W. H., KUAYE, A. Y. The quality of Minas Frescal cheese produced by different technological processes. Food Control, v. 18, n. 3, p. 262267, 2007.

COSTA DIAS, M. A. et al. On the implementation of good manufacturing practices in a small processing unity of Mozzarella cheese in Brazil. Food Control, v. 24, n. 1, p. 199-205, 2012.

FEITOSA, T. et al. Pesquisa de Salmonella sp., Listeria sp. e microrganismos indicadores higiênico-sanitários em queijos produzidos no estado do Rio Grande do Norte. Ciência e Tecnologia de Alimentos, v. 23, supl, p. 162-165, 2003.

FERREIRA, R. M. et al. Quantificação de coliformes totais e termotolerantes em queijos Minas Frescal artesanal. PUBVET, v. 5, n. 5, art 1022, 2011.

FORSYTHE, S. J. Microbiologia da segurança alimentar. Porto Alegre: Artmed, 2002. 424 p.

FRANCO, B. D. G de M.; LANDGRAF, M. Microrganismos patogênicos de importância em alimentos. In: Microbiologia dos alimentos. São Paulo: Atheneu, 2008. cap. 4, p. 48-60.

JAKOBSEN, R. A. et al. Staphylococcus aureus and Listeria monocytogenes in Norwegian raw milk cheese production. Food Microbiology, v. 28, n. 3, p. 492-496, 2011.

KOMATSU, R. S. et al. Ocorrência de Staphylococcus coagulase positiva em queijos Minas Frescal produzidos em Uberlândia - MG. Bioscience Journal, v. 26, n. 2, p. 316-321, 2010.

KOUSTA, M. et al. Prevalence and sources of cheese contamination with pathogens at farm and processing levels. Food Control, v. 21, n. 6 , p. $805-815,2010$. 
LANDGRAF, M. Microrganismos indicadores. In: FRANCO, B. D. G. de M;LANDGRAF, M. Microbiologia dos alimentos. São Paulo: Atheneu, 2008. cap. 3, p. 27-31.

LOGUERCIO, A. P; ALEIXO, J. A. G. Microbiologia de queijos tipo Minas Frescal produzidos Artesanalmente. Ciência Hoje, v. 31, n. 6, p. 1063-1067, 2001.

MARTINS, E.; MOURA, C. Manual técnico na arte e princípios da fabricação de queijos. 2. ed. Alto Piquiri: Campana, 2010. p. 14-16, 65.

NUNES, M. M. et al. Investigation of food and water microbiological conditions and foodborne disease outbreaks in the Federal District, Brazil. Food Control, v. 34, n. 1, p. 235-240, 2013.

O'BRIEN, M et al. Occurrence of foodborne pathogens in Irish farmhouse cheese. Food Microbiology, v. 26, n. 8, p. 910-914, 2009.

PASSOS, A. D. et al. Avaliação microbiológica de queijos Minas Frescal comercializados nas cidades de Arapongas e Londrina - PR. Revista do Instituto de Laticínios Cândido Tostes, v. 64, n. 369, p. 48-54, 2009.

PENA, E. C. et al. Avaliação da qualidade microbiológica do queijo Minas Frescal fabricado em Minas Gerais em 2008. In: CONGRESSO NACIONAL DE LATICÍNIOS, 26., 2009, Juiz de Fora. Anais Eletrônicos... Juiz de Fora: EPAMIG/ILCT, 2009. 1 CDROM.

PICOLI, S.U. et al. Quantificação de coliformes, Staphylococcus aureus e mesófilos presentes em diferentes etapas da produção de queijos Frescal de leite de cabra em laticínios. Ciência e Tecnologia de Alimentos, v. 26, n. 1, p. 64-69, 2006.
RAMOS, S. M. N; COSTA, C. A. Ocorrência de Listeria monocytogenes em queijo artesanal tipo coalho comercializado na cidade de Manaus - AM, Brasil. Acta Amazonica, v. 33, n. 4, p. 613-618, 2003.

ROCHA, J. S.et al. Condições de processamento e comercialização de queijos de Minas Frescal. Arquivo Brasileiro de Medicina Veterinária e Zootecnia, v. 52, n. 2, p. 263-272, 2006.

SALOTTI, B. M. et al. Qualidade microbiológica do queijo Minas Frescal comercializado no município de Jaboticabal, SP, Brasil. Arquivos do Instituto Biológico, v. 73, n. 2, p. 171-175, 2006

SANTOS, A. S. dos. Queijo Minas artesanal da microrregião do Serro - MG: efeito da sazonalidade sobre a microbiota do leite cru e comportamento microbiológico durante a maturação. 2010. 67 p. Dissertação (Pós graduação em Zootecnia) - Universidade Federal dos Vales do Jequitinhonha e Mucuri, Diamantina, 2010.

SCHVARTZMAN, M. S. et al. Modeling the fate of Listeria monocytogenes during manufacture and ripening of smeared cheese made with pasteurized or raw milk. International Journal of Food Microbiology, v. 145, n. 1, p. 31-38, 2011.

SERIDAN, B. et al. Qualidade microbiológica de queijos produzidos em Minas Gerais. In: CONGRESSO NACIONAL DE LATICÍNIOS, 26., 2009, Juiz de Fora. Anais Eletrônicos, Juiz de Fora: EPAMIG/ILCT, 2009. 1 CD-ROM.

ZAFFARI, C. B. et al. Qualidade bacteriológica de queijos artesanais comercializados em estradas do litoral norte do Rio Grande do Sul, Brasil. Ciência Rural, v. 37, n. 3, p. 862-867, 2007. 